\title{
Effects of Activity Strategy Training on Pain and Physical Activity in Older Adults With Knee or Hip Osteoarthritis: A Pilot Study
}

\author{
SUSAN L. MURPHY, ${ }^{1}$ DEBRA M. STRASBURG, ${ }^{2}$ ANGELA K. LYDEN, ${ }^{2}$ DYLAN M. SMITH, ${ }^{1}$ \\ JESSICA F. KOLIBA, ${ }^{2}$ DINA P. DADABHOY, ${ }^{3}$ AND SUSAN M. WALLIS ${ }^{2}$
}

Objective. To examine effects of activity strategy training (AST), a structured rehabilitation program taught by occupational therapists and designed to teach adaptive strategies for symptom control and engagement in physical activity (PA). Methods. A randomized controlled pilot trial was conducted at 4 sites (3 senior housing facilities and 1 senior center) in southeastern, lower Michigan. Fifty-four older adults with hip or knee osteoarthritis (mean \pm SD age $75.3 \pm 7.1$ years) participated. At each site, older adults were randomly assigned to 1 of 2 programs: exercise plus AST (Ex + AST) or exercise plus health education (Ex + Ed). The programs involved 8 sessions over 4 weeks with 2 followup sessions over a 6-month period, and were conducted concurrently within each site. Pain, total PA and PA intensity (measured objectively by actigraphy and subjectively by the Community Healthy Activities Model Program for Seniors questionnaire), arthritis self-efficacy, and physical function were assessed at baseline and posttest.

Results. At posttest, participants who received Ex + AST had significantly higher levels of objective peak PA $(P=0.02)$ compared with participants who received Ex + Ed. Although not statistically significant, participants in Ex + AST tended to have larger pain decreases, increased total objective and subjective PA, and increased physical function. No effects were found for arthritis self-efficacy.

Conclusion. Although participants were involved in identical exercise programs, participants who received AST tended to have larger increases in PA at posttest compared with participants who received health education. Future studies will be needed to examine larger samples and long-term effects of AST.

\section{INTRODUCTION}

It is now recognized that positive health behaviors can impact the severity and course of chronic diseases. Engagement in physical activity (PA) in particular has wellestablished health benefits, including maintenance of joint health and decreased severity of other common chronic health conditions (1-4). Among adults with arthritis, participation in regular, vigorous PA was projected to reduce

ClinicalTrials.gov identifier: NCT00613678.

Supported by the National Center for Medical Rehabilitation Research (grant K01-HD-045293) and the Office of the Vice President for Research at the University of Michigan.

${ }^{1}$ Susan L. Murphy, ScD, OTR, Dylan M. Smith, PhD: University of Michigan and VA Ann Arbor Health Care System, Ann Arbor; ${ }^{2}$ Debra M. Strasburg, MS, PT, Angela K. Lyden, MS, Jessica F. Koliba, BA, Susan M. Wallis, MD: University of Michigan, Ann Arbor; ${ }^{3}$ Dina P. Dadabhoy, MD: Northwest Rheumatology, Elk Grove Village, Illinois.

Address correspondence to Susan L. Murphy, ScD, OTR, 300 North Ingalls Street, Institute of Gerontology, 9th Floor, Ann Arbor, MI 48109-2007. E-mail: sumurphy@umich.edu.

Submitted for publication January 31, 2008; accepted in revised form May 23, 2008. the rate of functional decline over a 2-year period by as much as one-third (5). Even participation in low-intensity activities in older adults with arthritis has been found to be protective against the development of difficulty in activities of daily living over a 2-year period (6). Despite the benefits of engaging in PA, adults with arthritis are less likely to engage in recommended levels of PA than adults without arthritis (7), and the percentage of people with arthritis in the US who are inactive ranges from $24 \%$ to $37 \%$ (7-9). Problems in promoting PA among people with arthritis include the associated chronic pain and fatigue symptoms that are often viewed as barriers to PA engagement and maintenance (10), lack of effective behavioral or performance strategies to minimize the impact of symptoms, and physical environmental factors such as uneven surfaces and lack of sidewalks limiting the ability to walk outdoors (11).

To our knowledge, no current evidence-based arthritis programs address both personal and environmental barriers to promote PA. Most PA programs for knee or hip osteoarthritis (OA) offer structured exercise and have been shown to have small to moderate effects on arthritis pain and physical disability (12-14). However, adherence to 
exercise typically wanes after participation. Although there is evidence that an extra adherence component in combination with exercise may be useful for sustaining positive PA outcomes (15), the importance of lifestyle PA promotion (that which occurs in typical daily routines) is another strategy of sustaining PA outcomes.

Lifestyle issues are often addressed through education and self-management programs such as the Arthritis SelfManagement Program (ASMP) (16), and these programs have demonstrated small positive effects on outcomes such as pain, arthritis self-efficacy, depression, and health care utilization (17-21). The ASMP was recently adapted to include a PA enhancement component, and compared with a usual care group, program participants had increased arthritis self-efficacy, decreased pain, and reported participation in light exercises at followup (22). However, the ASMP does not have components that directly address problems with daily activity performance within the natural activity or environmental context.

Given the growing consensus that reducing environmental barriers is necessary for disability prevention $(23,24)$, it is now critical to examine the effectiveness of interventions that address not only physical problems, but also specific environmental and behavioral issues that interfere with activity engagement. This treatment approach is typical in occupational therapy (OT), and although it is considered extremely important $(25,26)$, to our knowledge no structured OT interventions have been tested among adults with knee or hip OA. Clark et al (27), in a randomized controlled trial of a 9-month intervention, provide the strongest evidence for the effectiveness of this type of treatment. In that study, older adults at senior housing sites participated in an OT intervention, a social activity group, or a control group. The OT group participated in group discussions, exercises, and practiced techniques to enhance activity engagement. Compared with the social activity and control groups, the OT group had significant positive effects on quality of life, functional status, and life satisfaction after intervention. These effects were sustained at 6-month followup (28). However, this study is limited in that it was not targeted specifically to adults with $\mathrm{OA}$ and is difficult to disseminate given the intervention's long length.

In this study, we tested the effectiveness of an occupational therapist-led program of exercise coupled with a component called activity strategy training (AST). AST involved active practice of techniques geared toward specific problems experienced by people with OA within the context of activity performance (such as joint protection and body mechanics). The behavioral strategies taught are based on content of coping skills training that specifically relates to activity performance (e.g., activity pacing, adding valued activities to daily routines) (29) and are commonly taught by occupational therapists to patients with chronic pain (30). We hypothesized that the exercise plus AST (Ex + AST) program would be more effective at reducing pain and increasing PA compared with an exercise plus health education $(\mathrm{Ex}+\mathrm{Ed})$ program. In addition, we hypothesized that the Ex + AST program would have more positive effects on secondary outcomes of arthritis self-efficacy and physical function compared with the Ex + Ed program.

\section{PARTICIPANTS AND METHODS}

Sample. Participants were recruited through fliers and on-site presentations at 3 local senior housing facilities and 1 senior center. Older adults were eligible for the study if they had symptomatic hip or knee OA as determined by American College of Rheumatology clinical criteria $(31,32)$ through an on-site examination by one of our study rheumatologists (DPD or SMW), and if they reported OA symptoms (i.e., pain, stiffness, fatigue) that caused difficulty or the need for personal assistance in at least 1 of 4 activities of daily living (i.e., bathing, transferring, toileting, walking). Participants also needed to be age $\geq 62$ years, ambulate with or without a walking aid, be Englishspeaking, and have no significant cognitive impairment (score of $\geq 5$ on the 6-Item Screener) (33). Older adults were excluded if they had hip or knee surgery within the previous 9 months, had a condition in which exercise would be contraindicated (e.g., uncontrolled hypertension, recent surgery, severe pain during exercise), had dementia, or were unable to give consent.

Procedure. Participants were randomly assigned after baseline assessment at each site into 1 of the 2 interventions (Ex + AST or Ex + Ed) in blocks of 2 using a random digit table. Recruitment began in September 2006 and ended in October 2007. The 2 interventions were equivalent in the amount of treatment time (1.5-hour sessions 2 times a week for 4 weeks) and in the exercise provided. The interventions were conducted in a small-group format by 2 group leaders. However, the Ex + AST intervention replaced 1 group session with 1 individualized session at a participant's residence for the purpose of examining in-home strategies for performing daily activities. The group sessions of Ex + AST were conducted by 2 OT interventionists, and the individual sessions were conducted by either occupational therapist. The group sessions of Ex + Ed were conducted by 2 health education interventionists who had many years of experience working with older adults. After the 8 sessions of intervention, groups underwent posttest assessments $(\sim 6$ weeks after baseline). During the next 6 months, participants met for 2 additional group sessions (spaced 2 months apart) to review the exercise program and highlight main points from the education or AST components. Participants then returned for followup testing 6 months after baseline. Only baseline to posttest outcomes are presented here. All testing was done at each site by trained assessors blinded to the group assignment of participants.

Exercise intervention content. The exercise program provided in both the Ex + AST and Ex + Ed interventions consisted of progressive resistance exercises, using ankle cuff weights in which extra weight could be added. The exercise program was designed for people with knee and hip OA by the physical therapist on our study team (DMS), and she tailored the program for individual participants as needed. Most participants began the program with 
2-pound weights. The program took 45 minutes to perform, including warm-up and cool-down stretching exercises. A resistance exercise program was chosen because it could be carried out indoors, which could promote adherence in the winter months and in neighborhoods where residents had concerns about their personal safety. At the end of the 8 sessions, all participants were given a detailed home program and extra add-in weights and were encouraged to continue with the exercises.

Health education and AST content. After the exercise period each session, either health education or AST was provided. For each intervention, a detailed written protocol was developed for group leaders and course packets were provided for participants. All group leaders were first trained by one of the authors (SLM) in the use of the protocols.

The health education program of the Ex + Ed intervention was based on educational materials from the Arthritis Foundation. These materials served as the primary topic for group discussion during each session (such as managing pain, the importance of exercise, diet, and arthritis, and medication options).

The AST sessions involved education, group discussion, and demonstration and practice of techniques to facilitate activity performance. Participants practiced strategies for symptom management such as activity pacing, joint protection, body mechanics, and transfer techniques. PA enhancement was encouraged by addressing individual barriers and group problem solving to build in additional PA and other valued activities into daily routines. In the home session, one OT group leader met with each participant and evaluated specific functional transfers such as shower/bath, toilet, indoor walking, and stair use (if applicable) using the Performance Assessment of Self-Care Skills (34). Results of this assessment were used to guide individualized instruction on in-home strategies for managing arthritis. Low-cost adaptive equipment (such as a reacher, raised toilet seat, adapted can opener) was provided for participants as prescribed by the occupational therapist to facilitate arthritis management.

Measures. Demographic and health status information (i.e., education, marital status, race, body mass index, number of chronic conditions, number of painful or stiff joints) was collected during the baseline assessment. At both assessment periods, participants underwent physical performance testing and were given questionnaires to complete. In addition, objective PA was assessed during a 3-day home period with an actigraph accelerometer (Actiwatch-S; Mini-Mitter, Bend, OR). Assessors retrieved questionnaires and the actigraph 1 week following the assessment visit. In this study, the primary outcomes were pain and PA and secondary outcomes were arthritis selfefficacy and physical function.

Primary outcomes. Pain was assessed by the Western Ontario and McMaster Universities Osteoarthritis Index (WOMAC), a validated, disease-specific questionnaire (35). Subjective and objective measures of PA intensity and total PA were also assessed. The Community Healthy Activities Model Program for Seniors (CHAMPS) question- naire (36) was used to ascertain weekly participation in light, moderate, and vigorous physical activities. The estimated kcal expended per week in both moderate (or greater) intensity (defined as $\geq 3$ metabolic equivalents; hereafter called CHAMPS moderate PA) and all activities were calculated (CHAMPS total PA), and these measures were shown to have adequate test-retest reliability ( $\mathrm{r}=$ 0.62, intraclass correlation coefficient 0.76) (36).

Objective PA was measured by a wrist-worn accelerometer (Actiwatch-S, Mini-Mitter). More details about this measure have been reported elsewhere $(37,38)$. Briefly, the Actiwatch-S contains a piezo-electrode that records movements of $\geq 0.01 \mathrm{~g}$, a level of force that is sensitive enough to capture very minute movements. The actigraph samples acceleration changes 32 times per second, and the peak value is added to an accumulated value over a 15-second epoch, which is recorded as an activity count. The Actiwatch-S was worn for 3 days continuously at baseline and at posttest. Peak PA (largest activity count each day averaged over 3 days) was used as an objective measure of daily activity intensity. The total PA was the 3-day average of an aggregated daily activity score each day at times when a person was deemed awake and excluding missing data that occurred from temporary removal of the Actiwatch-S.

Secondary outcomes. The Arthritis Self-Efficacy Scale is a reliable, valid measure of certainty in handling pain due to OA (39). The pain scale and other symptom scales can be combined (39), and the resulting 11-item scale had an internal consistency of $\alpha=0.90$ for this sample. Physical function was assessed by the 6-Minute Walk Test (40) and the Timed Up and Go Test (41). Both assessments are commonly used and validated with older adults.

Statistical analysis. To examine the baseline differences of participants by group, we calculated each group's means and percentages and performed independent-sample $t$-tests. A natural log transformation was done when variables had a skewed distribution (e.g., CHAMPS total PA, objective peak PA, and objective total PA). Due to the high proportion of zeros for CHAMPS moderate PA, we dichotomized responses into groups of zero versus any energy expenditure in moderate- or greater-intensity activities (kcal/week) and performed a chi-square test to examine baseline differences by group. For all analyses examining change from baseline to posttest, we adjusted for the site at which the interventions were provided. We also initially adjusted for the number of sessions attended, because compliance to an exercise program is generally thought to be an important predictor of success; however, including this variable had little to no effect on our models so we subsequently dropped this variable from the analyses. General linear models were used to examine betweengroup differences in outcome variables from baseline to posttest. In these models, the main effect is time and the interaction of interest is time $\times$ group. Due to the small number of cases in this randomized controlled pilot trial that could affect power to detect small to moderate effects, the effect size $d$ is also presented. The magnitude of $d$ has been described as $0.2=$ small, $0.5=$ moderate, and $0.8=$ 


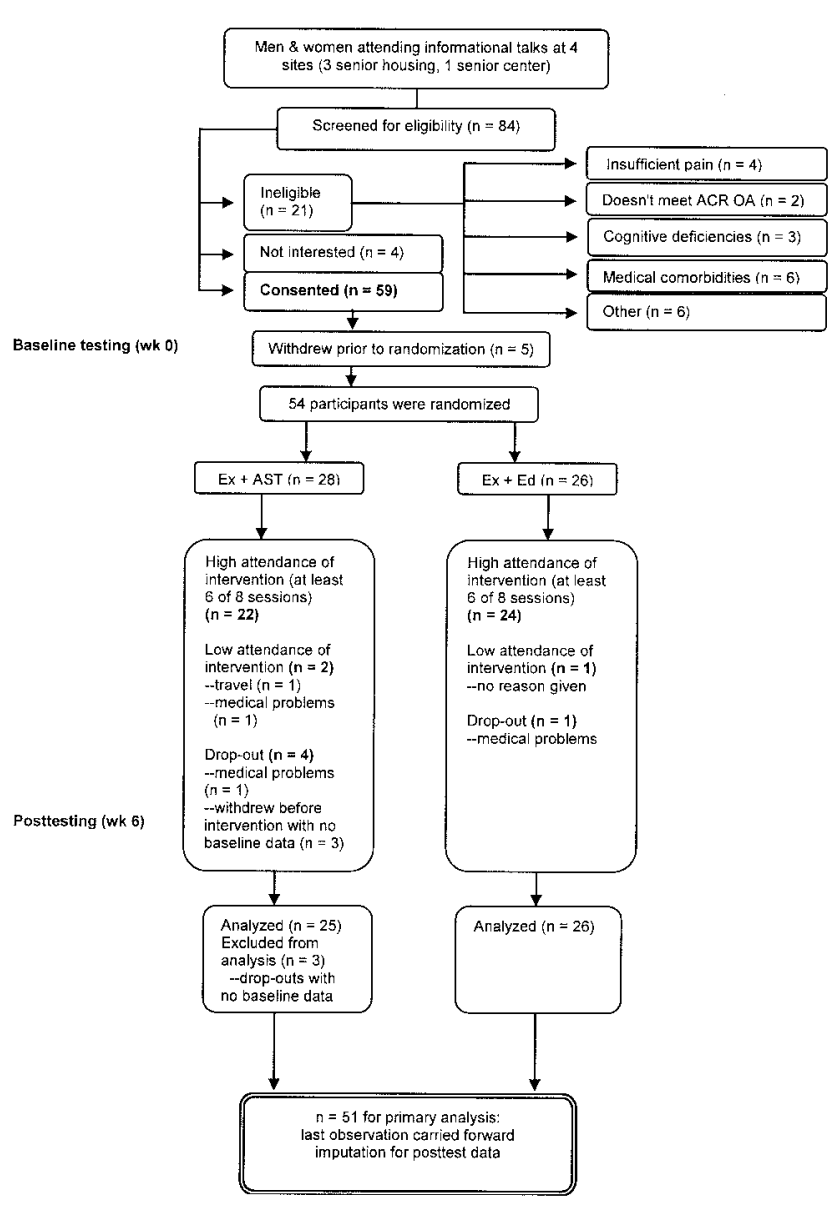

Figure 1. Adherence flow chart. ACR $=$ American College of Rheumatology; OA = osteoarthritis; Ex + AST = exercise plus activity strategy training; $\mathrm{Ex}+\mathrm{Ed}=$ exercise plus health education.

large (42). To examine change in CHAMPS moderate PA from baseline to posttest, we performed a binary logit model with group, baseline scores, number of sessions, and site as factors in the model. An intent-to-treat analysis was performed using the last observation carried forward (in this case, baseline values when posttest values were missing). Because of the similar findings between the in- tent-to-treat and as-treated analyses, only the intent-totreat analyses are presented. All statistical analyses were performed with SPSS, version 15.0 (SPSS, Chicago, IL).

\section{RESULTS}

Of 84 older adults screened, 64\% (n = 54) were randomized into 1 of the intervention groups. As the flow chart in Figure 1 shows, $25 \%$ of older adults did not meet eligibility criteria, $5 \%$ declined participation due to lack of interest, and $6 \%$ initially consented but later withdrew prior to randomization. Of the randomized participants, 5 withdrew from the study (4 from Ex + AST, 1 from Ex + Ed). Three participants withdrew before the intervention, citing reasons such as being new to the housing facility and too much burden of baseline assessment. Two other participants dropped out due to medical problems arising during the course of the program. The majority of randomized participants of the Ex + AST $(79 \%)$ and Ex + Ed $(92 \%)$ groups had high attendance in the program $(\geq 6$ out of 8 sessions).

Of all participants, $67 \%$ had knee OA, 22\% had knee and hip OA, and 11\% had hip OA only. The baseline characteristics of participants by group are shown in Table 1. Participants had a mean \pm SD age of $75.3 \pm 7.1$ years, and the majority were women, white, and had at least some college education. There were no significant differences between groups on any baseline measure. There were also no baseline group differences in primary and secondary outcomes (Table 2); however, participants in the Ex + AST group had a trend toward walking less distance during the 6-minute walk compared with participants in the Ex + Ed group (mean \pm SD $279.9 \pm 104.6$ versus $332.8 \pm 102.1$ meters; $P=0.07$ ).

Table 3 shows posttest values of primary and secondary outcomes (except for CHAMPS moderate PA, addressed below) and the effect of the Ex + AST versus Ex + Ed programs from baseline to posttest. Pain decreased in both groups at posttest (on WOMAC pain subscale, -1.2 for Ex + Ed and -1.5 for Ex + AST) (Figure 2). There was no statistically significant effect of pain reduction by group, and there was a small effect size $(d=0.03)$. For the primary PA outcomes, Figure 3 shows a comparison of base-

\begin{tabular}{|c|c|c|c|}
\hline & $\begin{array}{l}E x+E d \\
(n=26)\end{array}$ & $\begin{array}{c}\text { Ex }+ \text { AST } \\
(n=28)\end{array}$ & $\boldsymbol{P}$ \\
\hline Age, years & $74.8 \pm 7.3$ & $75.8 \pm 7.1$ & 0.65 \\
\hline Women, no. (\%) & $22(85)$ & $26(93)$ & 0.33 \\
\hline $\begin{array}{l}\text { Education (some college to advanced } \\
\text { degree), no. (\%) }\end{array}$ & $15(58)$ & $21(75)$ & 0.18 \\
\hline Married, no. (\%) & $5(19)$ & $7(25)$ & $0.75+$ \\
\hline White, no. (\%) & $23(89)$ & $26(93)$ & $0.66+$ \\
\hline Body mass index, $\mathrm{kg} / \mathrm{m}^{2}$ & $30.0 \pm 4.8$ & $30.1 \pm 6.5$ & 0.98 \\
\hline Total chronic conditions & $1.0 \pm 1.2$ & $1.5 \pm 1.4$ & 0.17 \\
\hline Number of painful or stiff joints & $4.6 \pm 2.1$ & $4.4 \pm 2.1$ & 0.79 \\
\hline
\end{tabular}




\begin{tabular}{|c|c|c|c|}
\hline & $\begin{array}{l}\text { Ex }+E d \\
(n=26)\end{array}$ & $\begin{array}{c}\mathrm{Ex}+\mathrm{AST} \\
(\mathrm{n}=28)\end{array}$ & $\boldsymbol{P}$ \\
\hline \multicolumn{4}{|l|}{ Pain } \\
\hline WOMAC pain subscale & $6.3 \pm 3.7$ & $6.7 \pm 3.6$ & 0.70 \\
\hline \multicolumn{4}{|l|}{ Physical activity } \\
\hline CHAMPS moderate PA† & $68(17 / 25)$ & $67(18 / 27)$ & 0.92 \\
\hline Objective peak PA, activity counts & $732.4 \pm 293.2$ & $699.0 \pm 303.0$ & 0.69 \\
\hline CHAMPS total PA, kcal/week & $2,700.5 \pm 2,901.1$ & $2,800 \pm 2,210.2$ & 0.89 \\
\hline Objective total PA, activity counts & $206,655 \pm 76,862$ & $202,532 \pm 97,397$ & 0.87 \\
\hline \multicolumn{4}{|l|}{ Arthritis self-efficacy } \\
\hline Pain and other symptoms & $7.2 \pm 1.8$ & $6.9 \pm 1.6$ & 0.60 \\
\hline \multicolumn{4}{|l|}{ Physical function } \\
\hline Timed Up and Go Test, seconds & $12.0 \pm 4.0$ & $14.1 \pm 7.5$ & 0.20 \\
\hline 6-Minute Walk Test, meters & $332.8 \pm 102.1$ & $279.9 \pm 104.6$ & 0.07 \\
\hline \multicolumn{4}{|c|}{$\begin{array}{l}\text { * Values are the mean } \pm \mathrm{SD} \text { unless otherwise indicated. Ex }+\mathrm{Ed}=\text { exercise plus health education; Ex }+ \\
\text { AST }=\text { exercise plus activity strategy training; WOMAC }=\text { Western Ontario and McMaster Universities } \\
\text { Osteoarthritis Index; CHAMPS = Community Healthy Activities Model Program for Seniors question- } \\
\text { naire; PA = physical activity. } \\
+ \text { Percentage of people engaged in any PA of moderate or high intensity. }\end{array}$} \\
\hline
\end{tabular}

line and posttest scores by group. Across groups at posttest, objective total PA, CHAMPS total PA, and objective peak PA declined in the Ex + Ed group and increased in the Ex + AST group. There was only a statistically significant effect of Ex + AST on peak PA $(\mathrm{F}[1,42]=5.9, P=$ $0.02)$, with a small to moderate effect size $(d=0.30)$. For the effect of group on CHAMPS moderate PA, results from the binary logit model showed a nonsignificant adjusted odds ratio of 0.44 (95\% confidence interval $0.09-2.19$ ) for the Ex + AST group. A higher proportion of people in the Ex + Ed group reported engaging in moderate or greater PA at posttest compared with those in the Ex + AST group.

For the secondary outcomes of arthritis self-efficacy and physical function, no statistically significant effects were found. Arthritis self-efficacy was virtually unchanged at posttest for the Ex + AST group and declined slightly in the $\operatorname{Ex}+\operatorname{Ed}$ group $(d=0)$. Of the physical function measures, 6-minute walk values showed an increase in average walking distance for both groups at posttest $(+14$ meters for Ex + Ed and +21 meters for Ex + AST; $d=$ $0.45)$.

\section{DISCUSSION}

This study was a randomized controlled pilot trial to begin to examine the effectiveness of an occupational therapistled intervention to promote symptom control and PA among people with knee and hip OA. We found that participants in the Ex + AST group had significantly higher objective peak PA at posttest compared with those in the Ex + Ed group, and this difference had a small to moderate effect size. Peak PA measured by actigraphy is considered to reflect activity intensity, so this increase may be a reflection of participation in activities of high intensity. However, further research is needed on how these objective PA patterns translate into daily life performance. It is somewhat difficult to compare the objective peak PA measure with our self-report measure of activity intensity be-

Table 3. Posttest values of primary and secondary outcomes by group and results of repeated-measures analysis of variance*

\begin{tabular}{|c|c|c|c|c|c|}
\hline & $\mathbf{E x}+\mathbf{E d}$ & Ex + AST & $\begin{array}{c}\text { Time } \times \text { group } \\
\text { F(df) }\end{array}$ & $\boldsymbol{P}$ & $d$ \\
\hline \multicolumn{6}{|l|}{ Pain } \\
\hline WOMAC pain & $5.1 \pm 4.0$ & $5.2 \pm 2.9$ & $0.6(1,43)$ & 0.47 & 0.03 \\
\hline \multicolumn{6}{|l|}{ Physical activity } \\
\hline Peak PA & $635.4 \pm 172$ & $739.3 \pm 271$ & $5.9(1,42)$ & 0.02 & 0.30 \\
\hline CHAMPS total PA & $2,589.6 \pm 1,778$ & $3,217.8 \pm 2,539$ & $0.002(1,44)$ & 0.97 & 0.09 \\
\hline Objective total PA & $205,247.6 \pm 84,856$ & $211,764.5 \pm 92,863$ & $3.3(1,42)$ & 0.08 & 0.24 \\
\hline \multicolumn{6}{|l|}{ Arthritis self-efficacy } \\
\hline Pain and other symptoms & $6.9 \pm 2.4$ & $6.9 \pm 2.1$ & $0.34(1,43)$ & 0.56 & 0 \\
\hline \multicolumn{6}{|l|}{ Physical function } \\
\hline Timed Up and Go Test, seconds & $11.7 \pm 3.9$ & $13.8 \pm 7.5$ & $0.04(1,44)$ & 0.85 & 0.35 \\
\hline 6-Minute Walk Test, meters & $346.6 \pm 97.6$ & $301.0 \pm 105.9$ & $0.32(1,46)$ & 0.57 & 0.45 \\
\hline
\end{tabular}

* All analyses were adjusted for the site where the intervention was given. Ex $+\mathrm{Ed}=$ exercise plus health education; Ex + AST $=$ exercise plus activity strategy training; WOMAC = Western Ontario and McMaster Universities Osteoarthritis Index; PA = physical activity; CHAMPS = Community Healthy Activities Model Program for Seniors questionnaire. 


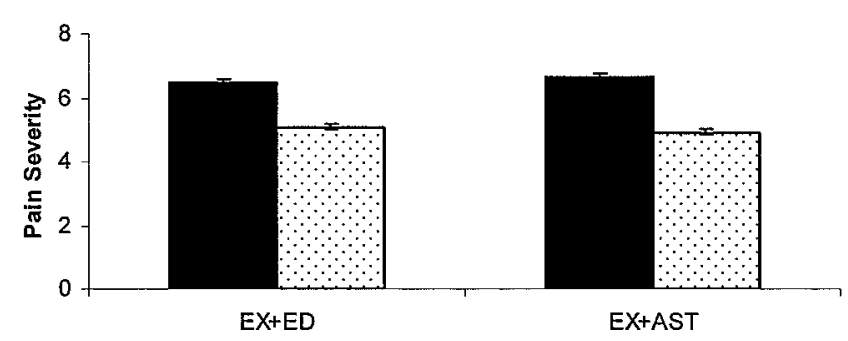

Figure 2. Comparison of baseline and posttest pain levels by treatment group using the Western Ontario and McMaster Universities Osteoarthritis Index (WOMAC). Solid bars show baseline; stippled bars show posttest. Error bars show the mean and SEM. $\mathrm{EX}+\mathrm{ED}=$ exercise plus health education; $\mathrm{EX}+\mathrm{AST}=$ exercise plus activity strategy training.

cause of how we dichotomized the self-report measure. Although nonsignificant, a higher percentage of people in the Ex + Ed group reported participation in moderate- or greater-intensity activities on the CHAMPS at posttest than those in the Ex + AST group. However, it is difficult to draw conclusions about this variable, given its distribution and the fact that our resulting dichotomization was not sensitive to other changes in moderate PA by group. In an exploratory analysis, we found that for the subset of people already engaging in CHAMPS moderate PA at baseline, there were actually larger posttest activity values in CHAMPS moderate PA in the Ex + AST group ( $\mathrm{n}=17$, mean \pm SD 2,198 $\pm 1,867 \mathrm{kcal} /$ week) compared with the Ex + Ed group $(\mathrm{n}=20,1,126 \pm 1,140 \mathrm{kcal} /$ week; $t[35]=$ $-2.14, P<0.05)$. In addition, we found a tendency for larger decreases in pain and increases in PA for the Ex + AST group compared with the Ex + Ed group.

The differences in our objective and subjective measurements of PA may have implications for future PA assessment. In our study, a major goal of the Ex + AST interven-

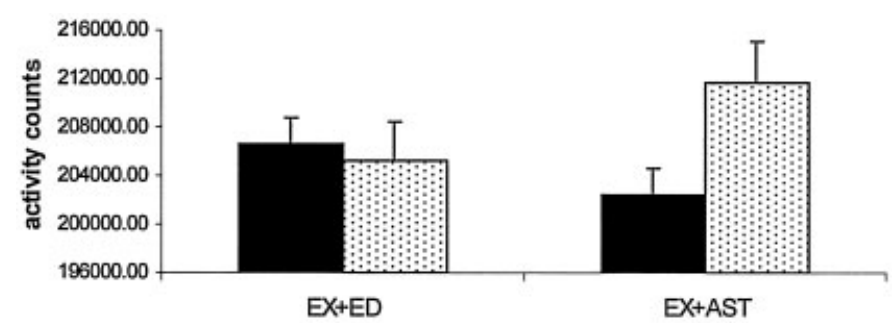

A

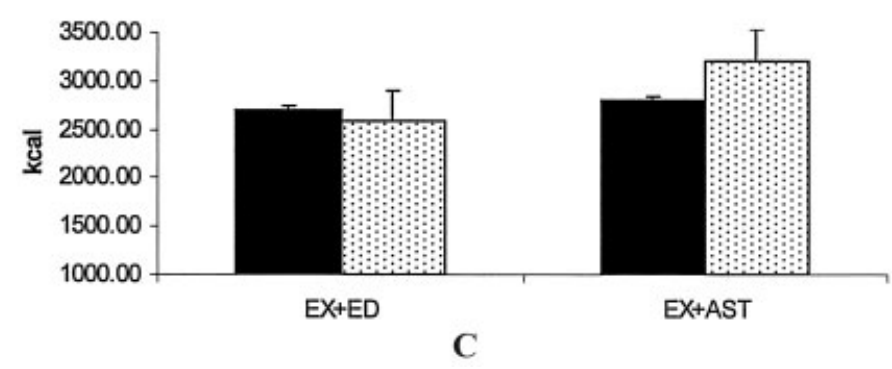

tion was to help people incorporate more PA (such as extra walking) into their daily routines. This type of lifestyle PA has been associated with improved mortality risk (43), physical fitness (44), and reduced pain and increased functioning in breast cancer survivors (45), but PA measured through self-report may not adequately detect these changes. Increases in nonexercise PA are likely to be more easily detected using an objective measure such as actigraphy. It is interesting to note that although self-efficacy tends to increase in education interventions, mean selfefficacy was virtually unchanged in both groups at posttest. Based on closer examination of our data, there was a change in this variable for many participants, either in a positive or negative direction, which may have attenuated any effects. Further research is needed to identify people who most benefit from this type of intervention.

Although we did not achieve statistical significance on most measures, we believe that the initial trends in changes of outcomes of Ex + AST compared with Ex + Ed are encouraging. This study was performed primarily to test feasibility of a multisite trial, and therefore, was not powered to detect changes in outcomes such as self-reported pain. Despite being underpowered, this trial was rigorously controlled by the detailed written protocol for replication, training of group leaders, and blinding of assessors. In order to best control for differences among cohorts at specific housing sites, we chose to run both types of interventions concurrently at each site. This type of design has the potential for contamination. Despite this limitation, it appears that there was low contamination in this study (of 47 who responded to the exit interview, only 3 reported speaking to a member of the other intervention group about the content of their program). Although we felt participants in the Ex + Ed intervention would likely experience some benefits, we included this type of group

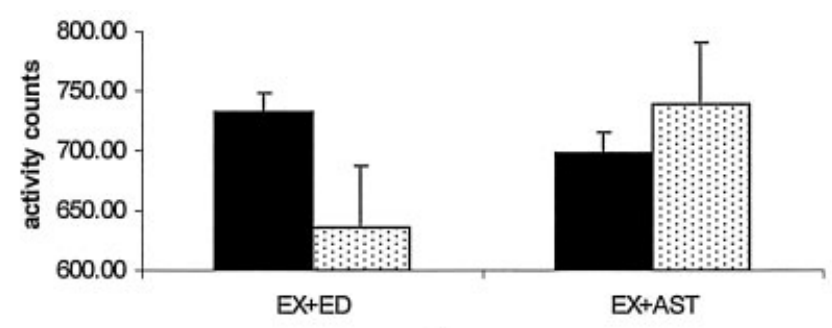

B

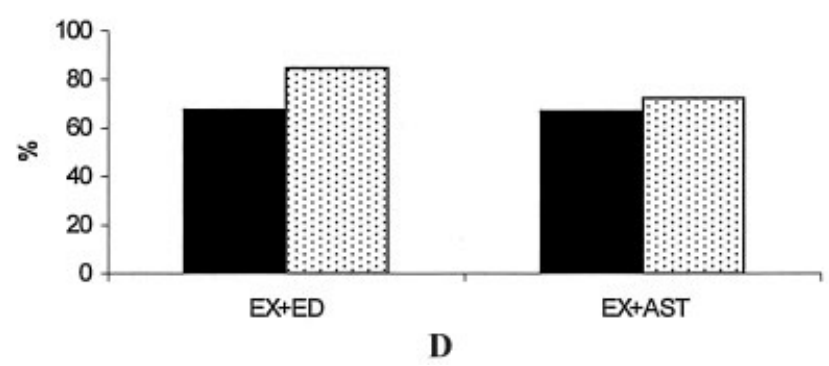

Figure 3. Comparisons of baseline and posttest objective and subjective physical activity (PA) scores by treatment group. A, Objective total PA and B, Objective peak PA $(P=0.02)$, both measured by actigraph accelerometer (activity counts). C, Community Healthy Activities Model Program for Seniors (CHAMPS) total PA (kcal/week). D, CHAMPS moderate PA is the percentage of people who participate in moderate- or greater-intensity activities. Solid bars show baseline; stippled bars show posttest. Error bars show the mean and SEM. $\mathrm{EX}+\mathrm{ED}=$ exercise plus health education; $\mathrm{EX}+\mathrm{AST}=$ exercise plus activity strategy training. 
for adequate comparison because it ensured that total treatment time was the same between the 2 groups. Controlling for treatment time is considered necessary for treatment fidelity in intervention studies of health behavior change (46). In addition, we believed that it provided the best comparison group to examine the effectiveness of AST, which is at times similar in content, but is more tailored to the individual and focused on problem-solving in the environment. However, it is possible that the Ex + AST program provided more intense treatment because it included an individualized home visit. This felt like a necessary tradeoff in our study design, because although we wanted a strong comparison group, our goal was to examine the role of OT in improving outcomes for older adults with OA. This role typically includes addressing clients' needs within their home environment. Another limitation of this design is the potential for an effect due to differences in group leaders. In this study, we had a small group of leaders ( 4 in the Ex + AST group and 3 in the Ex + Ed group) who took turns as primary group leaders at different sites, which likely reduced the differential effect of group leaders. Lastly, because our sample was predominantly white women who were well educated, findings are limited in generalizability to this group.

In summary, this study provides initial evidence for the effect of Ex + AST on increases in objective activity intensity for people with knee and hip OA. Replication will be needed in a larger sample to fully examine the effects of AST on the primary and secondary outcomes.

\section{ACKNOWLEDGMENTS}

We thank Neil Alexander, MD, for reviewing earlier drafts of this manuscript. We also thank Elizabeth Walker-Peterson, MPH, OTR/L, for consultation on the intervention content, Beverly Wolfe, OTR, Yael Ganet, MS, OTR, Naomi Gilbert, MS, OTR, Bradley Grincewicz, MPH, and Cynthia Torges, PhD, for their roles as group leaders, and Eric Pear, MS for help with data collection.

\section{AUTHOR CONTRIBUTIONS}

Dr. Murphy had full access to all of the data in the study and takes responsibility for the integrity of the data and the accuracy of the data analysis.

Study design. Murphy, Smith.

Acquisition of data. Strasburg, Koliba, Wallis.

Analysis and interpretation of data. Murphy, Lyden, Smith, Koliba.

Manuscript preparation. Murphy, Strasburg, Lyden, Smith.

Statistical analysis. Murphy, Lyden, Smith.

Development of Ex + Ed program. Murphy, Strasburg.

Development of recruitment guidelines (ACR clinical criteria). Dadabhoy, Wallis.

\section{REFERENCES}

1. Pate RR, Pratt M, Blair SN, Haskell WL, Macera CA, Bouchard $\mathrm{C}$, et al. Physical activity and public health: a recommendation from the Centers for Disease Control and Prevention and the American College of Sports Medicine. JAMA 1995;273: $402-7$.

2. Taylor AH, Cable NT, Faulkner G, Hillsdon M, Narici M, Van Der Bij AK. Physical activity and older adults: a review of health benefits and effectiveness of interventions. J Sports Sci 2004;22:703-25.

3. Kahn EB, Ramsey LT, Brownson RC, Heath GW, Howze EH, Powell KE, et al. The effectiveness of interventions to increase physical activity: a systematic review. Am J Prev Med 2002;22 Suppl 4:73-107.

4. Karmisholt K, Gyntelberg F, Gotzche PC. Physical activity for primary prevention of disease: systematic reviews of randomised clinical trials. Dan Med Bull 2005;52:86-9.

5. Dunlop DD, Semanik P, Song J, Manheim LM, Shih V, Chang RW. Risk factors for functional decline in older adults with arthritis. Arthritis Rheum 2005;52:1274-82.

6. Feinglass J, Thompson JA, He XZ, Witt W, Chang RW, Baker DW. Effect of physical activity on functional status among older middle-age adults with arthritis. Arthritis Rheum 2005; 53:879-85.

7. Shih M, Hootman JM, Kruger J, Helmick CG. Physical activity in men and women with arthritis: National Health Interview Survey, 2002. Am J Prev Med 2006;30:385-93.

8. Hootman JM, Macera CA, Ham SA, Helmick CG, Sniezek JE. Physical activity levels among the general US adult population and in adults with and without arthritis. Arthritis Rheum 2003;49:129-35.

9. Fontaine KR, Heo M, Bathon J. Are US adults with arthritis meeting public health recommendations for physical activity? Arthritis Rheum 2004;50:624-8.

10. Wilcox S, Der Ananian C, Abbott J, Vrazel J, Ramsey C, Sharpe PA, et al. Perceived exercise barriers, enablers, and benefits among exercising and nonexercising adults with arthritis: results from a qualitative study. Arthritis Rheum 2006;55: 616-27.

11. Martin KR, Schoster B, Shreffler JH, Meier A, Callahan LF. Perceived barriers to physical activity among North Carolinians with arthritis: findings from a mixed-methodology approach. N C Med J 2007;68:404-12.

12. Jamtvedt G, Dahm KT, Christie A, Moe RH, Haavardsholm E, Holm I, et al. Physical therapy interventions for patients with osteoarthritis of the knee: an overview of systematic reviews. Phys Ther 2008;88:123-36.

13. Van Baar ME, Assendelft WJ, Dekker J, Oostendorp RA, Bijlsma JW. Effectiveness of exercise therapy in patients with osteoarthritis of the hip or knee: a systematic review of randomized clinical trials. Arthritis Rheum 1999;42:1361-9.

14. Fransen M, McConnell S, Bell M. Exercise for osteoarthritis of the hip or knee. Cochrane Database Syst Rev 2001;3: CD004286.

15. Hughes SL, Seymour RB, Campbell R, Pollak N, Huber G, Sharma L. Impact of the fit and strong intervention on older adults with osteoarthritis. Gerontologist 2004;44:217-28.

16. Lorig K, Lubeck D, Kraines RG, Seleznick M, Holman HR. Outcomes of self-help education for patients with arthritis. Arthritis Rheum 1985;28:680-5.

17. Hawley DJ. Psycho-educational interventions in the treatment of arthritis. Baillieres Clin Rheumatol 1995;9:803-23.

18. Keefe FJ, Caldwell DS, Williams DA, Gil KM, Mitchell D, Robertson C, et al. Pain coping skills training in the measurement of knee pain II: follow-up results. Behav Ther 1990;21: $435-47$.

19. Lorig KR, Mazonson PD, Holman HR. Evidence suggesting that health education for self-management in patients with chronic arthritis has sustained health benefits while reducing health care costs. Arthritis Rheum 1993;36:439-46.

20. Superio-Cabuslay E, Ward MM, Lorig KR. Patient education interventions in osteoarthritis and rheumatoid arthritis: a meta-analytic comparison with nonsteroidal antiinflammatory drug treatment. Arthritis Care Res 1996;9:292-301.

21. Warsi A, Wang PS, LaValley MP, Avorn J, Solomon DH. Self-management education programs in chronic disease: a systematic review and methodological critique of the literature. Arch Intern Med 2004;164:1641-9.

22. Yip YB, Sit JW, Fung KK, Wong DY, Chong SY, Chung LH, et al. Effects of a self-management arthritis programme with an added exercise component for osteoarthritic knee: randomized controlled trial. J Adv Nurs 2007;59:20-8. 
23. Clarke AK. Effectiveness of rehabilitation in arthritis. Clin Rehabil 1999;13 Suppl 1:51-62.

24. Jette AM. Disablement outcomes in geriatric rehabilitation. Med Care 1997;35 Suppl 6:JS28-37.

25. Balint G, Szebenyi B. Non-pharmacological therapies in osteoarthritis. Baillieres Clin Rheumatol 1997;11:795-815.

26. Moran ME. Osteoarthritis and occupational therapy intervention. Phys Med Rehabil State Art Rev 2001;15:65-81.

27. Clark F, Azen SP, Zemke R, Jackson J, Carlson M, Mandel D, et al. Occupational therapy for independent living older adults: a randomized controlled trial. JAMA 1997;278: 1321-6.

28. Clark F, Azen SP, Carlson M, Mandel D, LaBree L, Hay J, et al. Embedding health-promoting changes into the daily lives of independent-living older adults: long-term follow-up of occupational therapy intervention. J Gerontol B Psychol Sci Soc Sci 2001;56:60-3.

29. Keefe FJ, Caldwell DS, Williams DA, Gil KM, Mitchell D, Robertson $\mathrm{C}$, et al. Pain coping skills training in the management of osteoarthritic knee pain: a comparative study. Behav Ther 1990;21:49-62.

30. Strong J. Chronic pain: the occupational therapist's perspective. New York: Churchill Livingstone; 1996.

31. Altman R, Asch E, Bloch D, Bole G, Borenstein D, Brandt K, et al. Development of criteria for the classification and reporting of osteoarthritis: classification of osteoarthritis of the knee. Arthritis Rheum 1986;29:1039-49.

32. Altman R, Alarcon G, Appelrouth D, Bloch D, Borenstein D, Brandt K, et al. The American College of Rheumatology criteria for the classification and reporting of osteoarthritis of the hip. Arthritis Rheum 1991;34:505-14.

33. Callahan CM, Unverzagt FW, Hui SL, Perkins AJ, Hendrie HC. Six-item screener to identify cognitive impairment among potential subjects for clinical research. Med Care 2002;40: 771-81.

34. Rogers JC, Holm MB. Performance assessment of self-care skills. Pittsburgh: University of Pittsburgh; 1994.

35. Bellamy N, Buchanan WW, Goldsmith CH, Campbell J, Stitt LW. Validation study of WOMAC: a health status instrument for measuring clinically important patient relevant outcomes to antirheumatic drug therapy in patients with osteoarthritis of the hip or knee. J Rheumatol 1988;15:1833-40.
36. Stewart AL, Mills KM, King AC, Haskell WL, Gillis D, Ritter PL. CHAMPS physical activity questionnaire for older adults: outcomes for interventions. Med Sci Sports Exerc 2001;33: $1126-41$

37. Gironda RJ, Lloyd J, Clark ME, Walker RL. Preliminary evaluation of reliability and criterion validity of Actiwatch-Score. J Rehabil Res Dev 2007;44:223-30.

38. Murphy SL, Smith DM, Clauw DJ, Alexander NB. The impact of momentary pain and fatigue on physical activity in women with osteoarthritis. Arthritis Rheum 2008;59:849-56.

39. Lorig K, Chastain RL, Ung E, Shoor S, Holman HR. Development and evaluation of a scale to measure perceived selfefficacy in people with arthritis. Arthritis Rheum 1989;32:3744.

40. Butland RJ, Pang J, Gross ER, Woodcock AA, Geddes DM. Two-, six-, and 12-minute walking tests in respiratory disease. Br Med J (Clin Res Ed) 1982;284:1607-8.

41. Podsiadlo D, Richardson S. The timed "Up \& Go": a test of basic functional mobility for frail elderly persons. J Am Geriatr Soc 1991;39:142-8.

42. Cohen J. Statistical power analysis for the behavioral sciences. Mahwah (NJ): Lawrence Erlbaum; 1988.

43. Matthews CE, Jurj AL, Shu XO, Li HL, Yang G, Li Q, et al. Influence of exercise, walking, cycling, and overall nonexercise physical activity on mortality in Chinese women. Am J Epidemiol 2007;165:1343-50.

44. Andersen RE, Wadden TA, Bartlett SJ, Zemel B, Verde TJ, Franckowiak SC. Effects of lifestyle activity vs structured aerobic exercise in obese women: a randomized trial. JAMA 1999;281:335-40.

45. Basen-Engquist K, Taylor CL, Rosenblum C, Smith MA, Shinn EH, Greisinger A, et al. Randomized pilot test of a lifestyle physical activity intervention for breast cancer survivors. Patient Educ Couns 2006;64:225-34.

46. Bellg AJ, Borrelli B, Resnick B, Hecht J, Minicucci DS, Ory M, et al, for the Treatment Fidelity Workgroup of the NIH Behavior Change Consortium. Enhancing treatment fidelity in health behavior change studies: best practices and recommendations from the NIH Behavior Change Consortium. Health Psychol 2004;23:443-51. 